method of increasing foot blood flow when this was reduced by the vasoconstricting effect of hyperbaric oxygen.

Normal feet have been assumed to have had a resting blood flow which ensured an oxygen availability to the tissues which was at least adequate for normal tissue requirements. Oxygen consumption has been used as a measurement of overall tissue metabolism. Guyton et al. (1964) suggested that oxygen is the most flow-limited tissue nutriment, and a blood flow that provides the tissues with adequate oxygen probably meets all other requirements. When oxygen availability was increased in the feet of normal subjects in this study there was no corresponding increase in oxygen consumption. It is unlikely that tissues with no oxygen need can be induced to consume more oxygen by simply increasing oxygen availability.

The peripheral vasoconstricting effect of hyperbaric oxygen alone (stage 2) reduced foot blood flow in normal subjects and offset the tenfold increase in $\mathrm{PaO}_{2}$. Oxygen availability was no higher in stage 2 than in stage 1 , and the vasoconstriction is believed to be a protective phenomenon shielding the tissues from the deleterious effect of hyperoxia. This phenomenon was also seen in both subgroups of ischaemic feet. The greatest fall in foot blood flow (47\%) occurred in the normal subjects, and with the significant fall in oxygen consumption these feet seem to have adjusted their metabolism to the prevailing blood flow. In stage 3 when the blood flow increased above the resting level the oxygen consumption of normal feet increased, but only to return to the normal resting level.

Subgroup L, ischaemic feet with an inital blood flow, significantly higher than normal, reduced their blood flow by only $11 \%$ when exposed to hyperbaric oxygen in stage 2 . This could be due to either an inability of the vascular system to vasoconstrict or an attempt to maintain or even increase the oxygen availability in response to the raised $\mathrm{PaO}_{2 .}$. When oxygen availability was significantly increased in stage 3 the oxygen consumption increased. These feet would therefore seem to have had an oxygen need not fully met by their resting blood flow and when more oxygen was made available it was immediately utilized by the tissues.

Subgroup $\mathrm{H}$, ischaemic feet with a high initial blood flow and therefore high oxygen availability, had an oxygen consumption higher than subgroup $L$ feet. When oxygen availability was increased in stage 3 there was no corresponding increase in oxygen consumption. These ischaemic feet appeared to have spontaneously increased their resting blood flow to meet an oxygen need, or at least to the limit of the tissues' ability to utilize oxygen.

There was little clinical difference between the ischaemic subgroups in length of history, type of lesion, or extent of lesion. A controlled environment, such as obtained in this study, was necessary to detect differences in mean dorsum forefoot skin temperature. The clinical skin temperature test of touch comparison between two feet, as performed at the bedside, generally failed to differentiate between the two ischaemic subgroups. None of the subgroup $H$ feet had a raised foot skin temperature that could be attributed to an active infective cellulitis.

The underlying mechanism for the high resting foot blood flow in ischaemic subjects with subgroup $\mathrm{H}$ feet, or perhaps for the failure of ischaemic subjects with subgroup $L$ feet to increase their foot blood flow high enough to meet the tissue oxygen needs, has not yet been examined in detail. The presence of ischaemic or, probably more correctly, anoxic lesions in an area with a high regional blood flow and oxygen availability merits further study. A blood flow may appear to be more than adequate for nutritional needs when measured at a regional level but may not necessarily be adequate at the tissue level. Furthermore, as Shepherd (1950) has shown, a regional blood flow that is normal in volume may be quite abnormal in pulsatile characteristics-a phenomenon worthy of detailed investigation in apparently ischaemic feet.

\section{REFERENCES}

Allwood, M. J., and Burry, H. S. (1954). Fournal of Physiology, 124, 345 Clark, R. S. J., and Hellon, R. F. (1957). Clinical Science, 16, 103

Guyton, A. C., Ross, J. M., Carrier, O., and Walker, J. R. (1964). Circulation Research, 15, Suppl. No $1, \mathrm{P} 60$.

McDowall, D. G., Ledingham, I.McA., Jacobson, I., and Norman, J. N (1965). Anesthesiology, 26, 720

Schraibman, I. G., and Ledingham, I.McA. (1969). British Journal of Surgery, 56, 295

Shepherd, J. T.'(1950). Clinical Science, 9, 49

Whitney, R. J. (1953). Fournal of Physiology, 121, 1.

\title{
Prevention of Postoperative Leg Vein Thrombosis by Electrical Muscle Stimulation. An Evaluation with ${ }^{125}$ I-Labelled Fibrinogen
}

\author{
N. L. BROWSE, ${ }^{*}$ M.D., F.R.C.S. ; D. NEGUS, $†$ D.M., M.CH., F.R.C.S.
}

\begin{abstract}
ummary: In a prospective trial of preventing deep vein thrombosis electrical stimulation of the calf muscles of one leg was used in 110 patients undergoing major surgery. Deep vein thrombosis was detected by means of the ${ }^{125}$ I-fibrinogen uptake test in nine of the stimulated legs and in 23 of the unstimulated legs. It is suggested that this technique, which is both simple and effective, should be used on all patients undergoing major surgery.
\end{abstract}

\section{Introduction}

The belief that stasis is a major factor in the development of deep vein thrombosis has prompted surgeons to attempt to

* Reader in Surgery and Deputy Director.

† Senior Surgical Registrar.

Surgical Unit, St. Thomas's Hospital, London S.E.1. increase blood flow in the deep veins of the leg, during and after surgical procedures, by a variety of methods. These include early ambulation (Nelson, 1944), raising of the legs (Pearson, 1954), elastic compression of the legs (Wilkins et al., 1952), exercise machines (Gibbs, 1959), and electrical stimulation of the calf muscles (Doran et al., 1964).

Doran et al. (1964) showed that the velocity of venous blood flow in the leg reached its lowest level during operation and argued that this was the most important period to try to increase it. They showed that the velocity of venous blood flow could be increased by stimulating the calf muscles with an intermittent galvanic current. Doran and White (1967) reported the results of a clinical trial of the effect of this method on the incidence of deep vein thrombosis and pulmonary embolism. Their results were encouraging but not wholly acceptable because the diagnosis of deep vein thrombosis was based on physical signs, a method of assessment 
which has been shown to be notoriously unreliable (Sevitt and Gallagher, 1959; Negus et al., 1969).

Since Doran's observations were published the ${ }^{125} \mathrm{I}-$ fibrinogen uptake test has been established as an accurate method of detecting thrombosis in the deep veins of the leg below the inguinal ligament (Flanc et al., 1968; Negus et al., 1968). This technique is eminently suitable for research projects, and here we report the results of a trial of the effectiveness of calf muscle stimulation in preventing postoperative deep vein thrombosis, using the ${ }^{125}$ I-fibrinogen uptake test as the means of diagnosis.

\section{Methods}

The trial was restricted to volunteers of both sexes over the age of 40 who were undergoing surgical operations of moderate or major severity. Premenopausal women were excluded in view of the remote possibility of genetic effects of the intravenous isotope. Patients having operations on the legs were excluded, as the ${ }^{125}$ I-fibrinogen uptake test is unreliable in the presence of a fresh wound or haematoma. Patients having aorta-iliac arterial surgery or any operation in which the iliac veins or vena cava were exposed and likely to be damaged were also excluded as this would have added an uncontrolled local cause for venous thrombosis. A history of a previous episode of deep vein thrombosis did not affect selection.

The details of the experiment were fully explained to the patients and their written consent was obtained.

\section{Calf Muscle Stimulation}

The stimulating current was provided by a mains-operated SS Electronics Diagnostic Stimulator Type V MkIII or by a battery-operated Medelec TS2 stimulator. The calf muscles were stimulated to contract briefly and intermittently every two seconds by a square-wave galvanic current transmitted by two electrodes, one attached to the back of the calf just below the lower border of the popliteal fossa and the other to the posterior surface of the lower third of the lower leg. The stimulating electrodes were thin sheets of tin plate, 12 by 9 $\mathrm{cm}$., covered with stockinet and liberally coated with "sloppy" electrode jelly. (The use of bare metal plates carries a risk of burning owing to uneven skin contact.)

The stimulating voltage was adjusted to produce a brisk plantar-flexion of the foot without violent movement of the leg. The pulse width was $30 \mathrm{msec}$. Pulses longer than this were only marginally more effective in producing good muscle contractions, and are theoretically more likely to produce skin erythema and blistering. Good muscle contractions were obtained with a potential difference of 15 volts in the lightly anaesthetized patient,. rising to 45 volts in the presence of neuromuscular blocking agents. (These voltages were measured with an estimated patient resistance of 1,000 ohms.) It was often necessary to adjust the voltage during the operation, especially after the administration and reversal of muscle relaxants, to keep the strength of the calf contraction constant.

The electrodes were applied, and stimulation was started, when the parient was placed on the operating table immediately after the induction of anaesthesia, and continued until the end of the operation. Most patients were awake and moving snontaneously within 15 minutes of the removal of the electrodes. It was not possible to continue stimulating after this as each stimulus causes an uncomfortable pricking sensation.

The diathermy plate was attached by a bandage to the thigh of the stimulated leg so that if it had any deleterious effect-for example, retarding the rate of venous blood flowit would oppose the effect of the stimulation and so weigh against its success.
Each patient was his own control, as only one leg was treated. The leg to be stimulated was chosen by random selection. Patients whose year of birth was an even number had the right leg stimulated, those with an odd number had the left leg stimulated. This provided a randomized matched controlled study.

\section{I-Fibrinogen Uptake Test}

The technique followed was that described by Negus $e t$ al. (1968). Potassium iodide $150 \mathrm{mg}$. was given by mouth 24 hours before operation and daily for three weeks afterwards to prevent the uptake of radioactive iodine by the thyroid gland.

Between one and eight hours after operation $100 \mathrm{mCi}$ of ${ }^{125}$ I-fibrinogen was injected intravenously. Scintillation counting at 4 -in. $(10-\mathrm{cm}$.) intervals over the main deep veins of the leg was performed on the first, third, and fifth postoperative days. Additional examinations were made if a positive reading was obtained. The radioactive count rate in legs was expressed as a percentage of the heart count. An absolute difference in count rate of more than $15 \%$ between adjacent points, or the same point on the other leg, which persisted or increased for more than 24 hours was taken to indicate the presence of underlying venous thrombosis. Phlebograms were not performed. The physical signs of deep vein thrombosis were ignored but care was taken to exclude superficial venous thrombosis as the reason for a raised radioactive count.

\section{Statistical Design of Trial}

It was considered appropriate to use a restricted sequential design because of the ethical need to avoid extensive experimentation. It was estimated, from previous observations (Negus et al., 1969), that there would be an incidence of deep vein thrombosis of about $20 \%$. A restricted sequential design was prepared with $2 \alpha=0.05,1 \beta=0.95, \theta=0.826, \mathrm{~N}=31$ (for the notation see Armitage, 1960). The design was set up to detect $15 \%$ difference from $80 \%$ with type 1 and type 2 errors of 0.05 . The trial concluded when the sequentially plotted results had passed two points beyond the chosen upper boundary. In the sequential analysis only the unmatched observations were utilized. Thus occurrence of thrombosis in both the stimulated and the unstimulated leg and non-occurrence of thrombosis in both legs was not included.

\section{Results}

The trial was stopped when the sequential analysis (see Fig.) reached the line of $5 \%$ significance. At this point 110 patients had been studied and 16 had thrombosis in the nonstimulated leg only and two in the stimulated leg only. The age of the patients ranged from 40 to 81 years, with a mean of 60 years. There were 57 men and 53 women.

The operations performed are shown in Table I. No patient had any serious blood loss or hypotension during or after surgery. Most patients were ambulant and active within two or three days of operation. No special attention was paid to postoperative rehabilitation, but, as is our usual practice, all were encouraged to exercise and had chest physiotherapy.

\section{Incidence of Deep Vein Thrombosis}

Sixty-one left legs and 49 right legs were stimulated. Deep vein thrombosis was detected in the calf veins of one or both legs of 25 patients, an incidence of $23 \%$ (15 were men and 10 women). No thrombosis was detected in any patient under 50 years of age; no thrombosis was detected above the level of the knee joint; and no patient had any clinical evidence of pulmonary embolism. 


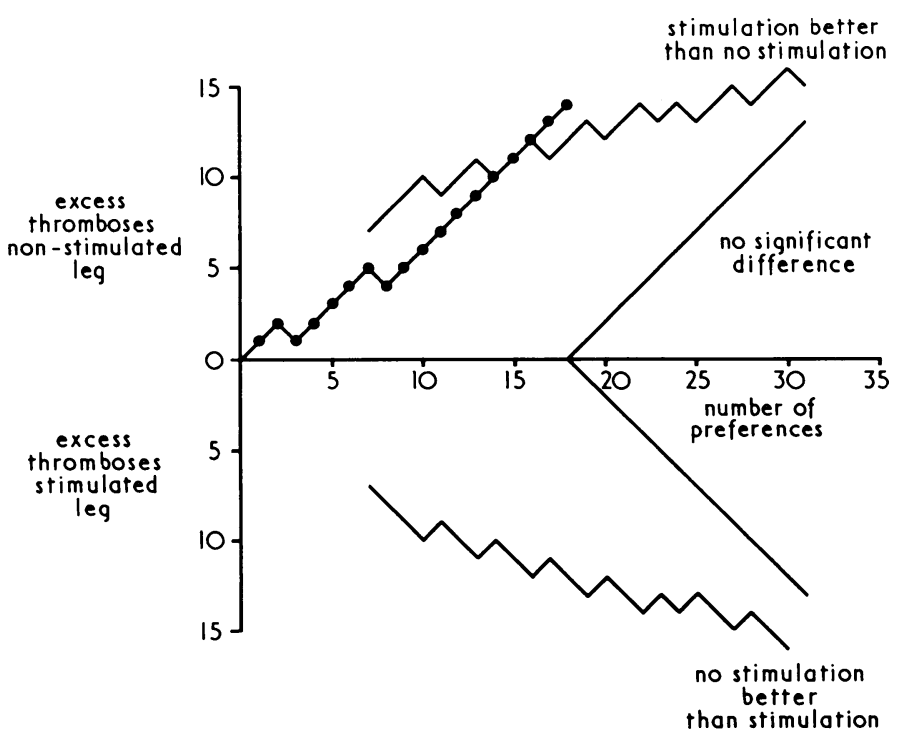

The sequential analysis used in this trial. The lines of significance correspond to a $\mathrm{P}$ value of $5 \%$. Only unilateral thromboses could be plotted in this manner; bilateral positives or negatives were excluded.

Thrombosis occurred in both legs of seven patients, in the stimulated leg only of two patients, and in the unstimulated leg only of 16 patients.

Thus there was thrombosis in nine $(8.2 \%)$ of the stimulated legs and in $23(20.9 \%)$ of the unstimulated legs. This is a reduction of $12.7 \%$ (absolute), or $61 \%$ (relative), in the incidence (per leg) of deep vein thrombosis. The thrombosis was first detected before the fourth postoperative day in 18 patients and between the fourth and sixth days in the remaining seven.

Deep vein thrombosis occurred in five of the stimulated left and four of the stimulated right legs (see Table II), and in

TABLe I.-Analysis of Operations Performed

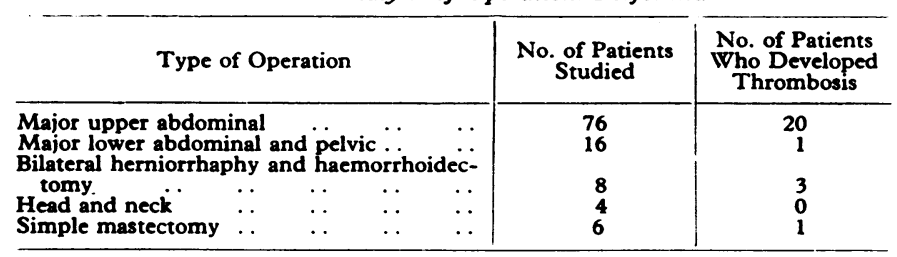

TABLE II.-Distribution of Deep Vein Thrombosis

\begin{tabular}{|c|c|c|c|c|c|c|c|}
\hline \multirow{2}{*}{\multicolumn{5}{|c|}{ Stimulated Leg }} & \multicolumn{3}{|c|}{ Deep Vein Thrombosis } \\
\hline & & & & & Present & \multirow{2}{*}{$\begin{array}{l}\text { Absent } \\
56(91.8 \%) \\
45(91.8 \%)\end{array}$} & \multirow{2}{*}{\begin{tabular}{c|} 
Total \\
$61(100 \%)$ \\
$49(100 \%)$
\end{tabular}} \\
\hline $\begin{array}{l}\text { Left .. } \\
\text { Right. . }\end{array}$ & 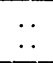 & 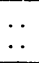 & 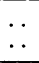 & $\ldots$ & $\begin{array}{ll}5 & (8 \cdot 2 \%) \\
4 & (8 \cdot 2 \%)\end{array}$ & & \\
\hline Total & $\ldots$ & .. & $\ldots$ & $\ldots$ & $9(8 \cdot 2 \%)$ & $101(91 \cdot 8 \%)$ & $110(100 \%)$ \\
\hline
\end{tabular}

Significance of incidence of thrombosis between right and left legs $\chi^{2}=0.118$ (not significant, $P>0.05$ ).

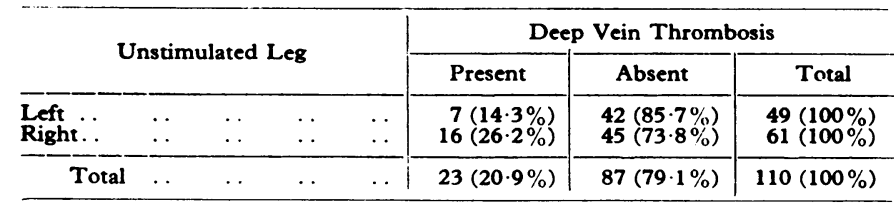
Significance of incidence of thrombosis between right and left legs $\chi^{2}=1.677$
(not significant, $P>0.05$ ).

Table III.-Incidence of Deep Vein Thrombosis in Surgical Patients

\begin{tabular}{|c|c|c|c|c|}
\hline Series & Bilateral & Right Leg & Left Leg & Total \\
\hline $\begin{array}{l}\text { Middlesex Hospital (280 patients) } \\
\text { (Kemble, 1970) }\end{array}$ & $8 \%$ & $7 \%$ & $13 \%$ & $28 \%$ \\
\hline $\begin{array}{l}\text { King's College Hospital }(215 \\
\text { patients) (Kakkar, 1970) } \\
\text { St. Thomas's Hospital (47 patients) } \\
\text { Mean of } 542 \text { patients }\end{array}$ & $\begin{aligned} 10 \% \\
11 \% \\
9 \%\end{aligned}$ & $\begin{array}{l}12 \% \\
11 \% \\
9 \%\end{array}$ & $\begin{array}{r}7 \% \\
6 \% \\
10 \%\end{array}$ & $\begin{array}{l}29 \% \\
28 \% \\
28 \%\end{array}$ \\
\hline
\end{tabular}

16 of the unstimulated right and 7 of the unstimulated left legs. Though there is some difference in the incidence of thrombosis between the right and left legs in the unstimulated legs, it is not of such magnitude as to be of statistical significance $\left(\chi^{2}>0.05\right)$. In this trial there is no statistically significant evidence of a difference between the incidence of rightsided and left-sided thrombosis.

As this study depends on the assumption that the incidence of calf vein thrombosis is equal in both legs we asked our colleagues at Middlesex Hospital and King's College Hospital for their figures. These data are presented in Table III. The mean figures of these three prospective studies show that nearly one-third of all patients undergoing surgery develop a deep vein thrombosis and that this occurs in both legs in one-third and in one leg equally in the remaining two-thirds. As the incidence of calf vein thrombosis is the same in both legs our method of matching one leg against the other is acceptable and the difference between the incidence of thrombosis in the stimulated and non-stimulated legs is highly significant.

The final analysis of all 110 patients, 23 with thrombosis in the non-stimulated leg and nine in the stimulated leg, was undertaken using McNemar's test of matched pairs to take into account the fact that the two treatment groups (stimulation and no stimulation) followed a natural system of pairing. When analysed in this manner the results provide statistically significant evidence that calf muscle stimulation does reduce the incidence of deep vein thrombosis: $x^{2}=9.39$ $(0.001<\mathrm{P}<0.01)$.

\section{Discussion}

This study, using an objective method of detecing deep vein thrombosis, has confirmed Doran and White's (1967) observations that stimulation of the calf muscles during a surgical operation significantly reduces the incidence of deep vein thrombosis. Since their work was published studies using the ${ }^{125}$ I-fibrinogen method have shown that most postoperative venous thromboses are detectable very soon after operation (Flanc et al., 1968; Negus et al 1968), implying that the so-called "post"operative deep vein thrombosis is probably "intra"operative in origin, confirming their view that any prophylactic method should start during rather than after the operation.

Though the method of stimulation that we used significantly reduced the incidence of deep vein thrombosis it did not completely abolish it. We feel that the method of repeated brisk contractions of the calf muscles as described by Doran and White (1967) is more effective in promoting the "pump action" of the calf muscles and in increasing the velocity of venous blood flow than the technique of slower contractions described by Moloney and Fell (1968). We have not, however, compared the two methods. The "rapid contraction" method usually doubles the venous flow velocity from its resting level (Doran et al., 1964; Browse, Jackson, and Negus, unpublished observations).

The chief problems of using this method of prophylaxis are logistic. Four electrodes have to be attached to the patient before the operation begins, in addition to the diathermy plate, with all the attendant problems of electrical equipmen; in the operating theatre; but we have found this to be of little practical difficulty, as theatre technicians rapidly learn how to apply the electrodes and to regulate the stimulating voltage. We have experienced no skin blistering or burning when adhering to the precautions already mentioned. On two occasions the corner of one plate became uncovered and pressed hard into the skin, and small $(1 \mathrm{~cm}$. diameter) blisters appeared next day. This complication is completely avoidable by ensuring good, even contact through a protective covering and would be still less likely if the direction of the current was reversed with each stimulation. 
We used a square-wave galvanic current as described by Doran et al. (1964) because this form of stimulating current is most readily available in standard apparatus and easiest to measure in terms of duration and strength. Nevertheless, there is no reason why other forms of current, sine wave, triangular wave, or square wave of alternating polarity, should not be used, and one of these may ultimately prove more suitable.

The precise mechanism by which muscle stimula:ion reduces the incidence of deep vein thrombosis remains an unanswered question. Though simple abolition of venous stasis, by increasing the velocity of venous blood flow, may be important, other possible factors are the increase in arterial inflow-normally depressed during operation (Browse, 1962)-induced by the muscle contractions, and an increase in blood fibrinolytic activity which is known to be stimulated by muscle activity (Fearnley, 1965).

It can be argued that most of the deep vein thromboses detected by the ${ }^{125}$ I-fibrinogen uptake test are small, symptomless, and of little or no consequence to the patient. Even if this is true it is extremely likely that the more extensive dangerous thrombus develops from one of these small initial thrombi.

The venous thrombosis which most of ten gives rise to fatal pulmonary embolism develops in the upper femoral or iliac veins (Mavor and Galloway, 1967). No such thrombi have been detected in this trial. The ${ }^{125}$ I-fibrinogen uptake test is not accurate above the groin, but no patient has shown clinical evidence of either iliac vein occlusion or pulmonary embolism. It is reasonable to suppose that the twofold increase in the velocity of venous blood flow in the upper femoral vein produced by calf muscle stimulation will inhibit thrombus formation at this site if it does so in the more distal veins of the thigh and calf.

Pulmonary embolism is a common postoperative complication and has been held responsible for the death of about 1 in every 900 patients undergoing surgical operation (Pilcher, 1937; Murley, 1950), and deep calf vein thrombosis is often followed by venous incompetence which eventually causes chronic swelling and ulceration of the legs. The importance of adequate prophylaxis requires no further emphasis. Several methods of prophylaxis have been described (Browse, 1970). So far only anticoagulants (Sevitt and Gallagher, 1959), calf stimulation, and the infusion of dextran 70 (Ahlberg et al., 1968; Lambie et al., 1970) have shown encouraging results. Possibly the combination of an intravenous agent and calf muscle stimulation would provide the most effective prophylaxis, without the logistic problems and serious complications that abound when anticoagulants are used.

The high incidence of deep vein thrombosis during surgery and the serious effects of thrombus propagation and fragmentation make effective prophylaxis mandatory. This study has shown the simplicity and effectiveness of calf muscle stimulation, and we believe that this method should be used on all patients undergoing a major surgical operation.

We gratefully acknowledge the help of $\mathrm{Mr}$. T. Halil with the design of this trial and with the analysis of results. Mrs. A Taylor, Miss G. Gollop, and Miss R. Redford provided skilled technical help.

This research has been supported by a grant from the Medical Research Council.

We are grateful to Professor J. B. Kinmonth and Messrs. $R$ Nevin, H. F. Lockhart-Mummery, A. York Mason, and J. M. Edwards for allowing us to include in this trial patients under their care.

\section{REFERENCES}

Ahlberg, A., Nylander, G., Robertson, B., Cronberg, S., and Nilsson I. M. (1968). Acta Chirurgica Scandanavica, Suppl. No. 387, p. 83. Armitage, P. (1960). Sequential Medical Trials. Oxford, Blackwell Scientific. Browse, N. L. (1962). British Medical fournal, 1, 1714.

Browse, N. L. (1962). British Medical fournal, 1, 1714

Doran, F. S. A., Drury, M., and Sivyer, A. (1964). British fournal of Surgery $51,486$.

Doran, F. S. A., and White, H. M. (1967). British fournal of Surgery, 54, 686.

Doran, F. S. A., White, H. M., and Drury, M. (1970). British fournal of Surgery, 57, 20

Fearnley, G. R.'(1965). Fibrinolysis. London, Arnold.

Flanc, C., Kakkar, V. V., and Clarke, M. B. (1968). British fournal of Surgery, 55, 742 .

Gibbs, H. M. (1959). British Fournal of Surgery, 47, 282.

Kakkar, V. V. (1970). Personal communication.

Kemble, J. V. H. (1970). Personal communication.

Lambie, J. M., Barber, D. C., Dhall, D. P., and Matheson, H. A. (1970) British Medical fournal, 2, 144

Makin, G. S. (1969). British fournal of Surgery, 56, 373.

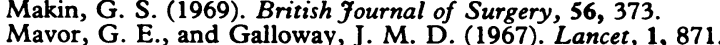

Moloney, G. E., and Fell, R. H. (1968). British Medical fournal, 4, 705

Murley, R. S. (1950). Annals of the Royal College of Surgeons of England, 6, 283.

Negus, D., Pinto, D. 'J., LeQuesne, L. P., Brown, N., and Chapman, M (1968). British fournal of Surgery, 55, 835.

Negus, D., Pinto, D. J., and Brown, N. (1969). Acta Chirurgica Belgica, 68 , 507.

Nelson, H. (1944). Archives of Surgery, 49, 1

Pearson, A. (1954). British Medical fournal, 1, 643.

Pilcher, R. (1937). British fournal of Surgery, 25, 42.

Sevitt, S., and Gallagher, N. (1959). Lancet, 2, 981.

Wilkins, R. W., Mixter, G., Stanton, J. R., and Litter, J. (1952). Neq" England fournal of Medicine, 246, 360.

\footnotetext{
* Senior Lecturer, University Department of Dermatology, Royal Victoria Infirmary, Newcastle upon Tyne NEl 4LP.

† Professor of Dermatology, University Department of Dermatology, Royal Victoria Infirmary, Newcastle upon Tyne NE1 4LP.
}

Qummary: The excretion in the urine of ${ }^{58} \mathrm{Co}$ after an $\sim$ oral dose of ${ }^{58} \mathrm{Co}$ vitamin $\mathrm{B}_{12}$ given together with intrinsic factor has been found to be reduced in a number of patients with psoriasis, eczema, and other less common dermatoses. There is a correlation between the abnormality and the extent of the rash. $A$ reduced glomerular filtration rate was found in a few of the patients in whom it was measured, and this must have been responsible, at least in part, for the reduced excretion of vitamin $B_{12}$ in these patients, but abnormal vitamin $B_{1: 2}$ excretion also occurred in the absence of immaired renal function. Our evidence is insufficient to show whether malabsorption or increased tissue utilization of vitamin $B_{1:}$ was the explanation in other cases. Certainly a number of patients had steatorrhoea, and in these it is most likely that malabsorption was the major factor. In patients without steatorrhoea a lone malabsorption of vitamin $B_{12}$ cannot be excluded. A decreased serum concentration of vitamin $B_{1,}$, was found in onlv one of the patients. 